\title{
Mitral durability after robotic mitral valve repair: Analysis of 200 consecutive mitral regurgitation repairs
}

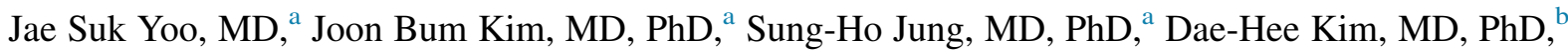 \\ Suk Jung Choo, MD, PhD, ${ }^{a}$ Cheol Hyun Chung, MD, PhD, ${ }^{a}$ and Jae Won Lee, MD, PhD ${ }^{\mathrm{a}}$
}

\begin{abstract}
Objectives: The study objective was to review a single-center experience on robotic mitral valve repair to treat mitral regurgitation, with a specific focus on midterm echocardiographic mitral durability. No data assessing the quality or durability of repaired mitral valves are currently available.
\end{abstract} Methods: A total of 200 patients who underwent robotic mitral regurgitation repair using the da Vinci system
(Intuitive Surgical, Inc, Sunnyvale, Calif) between August 2007 and December 2012 were evaluated. Serial
echocardiographic results and operative and procedural times were analyzed.

\begin{abstract}
Results: Mitral regurgitation repairs were successfully performed, and no or mild residual mitral regurgitation developed in $98.0 \%$ of patients, with no conversion to sternotomy. No in-hospital deaths occurred. Follow-up was completed in $96.5 \%$ of patients with a median of 31.4 months (interquartile range, 12.4-42.3 months). During follow-up, 4 late deaths, 2 strokes, 1 low cardiac output, 1 newly required dialysis, and 1 reoperation for mitral regurgitation occurred. Freedom from major adverse cardiac events at 5 years was $87.7 \% \pm 5.1 \%$. Regular echocardiographic follow-up (>6 months) was achieved in 187 patients $(93.5 \%)$. At a median of 29.6 months (interquartile range, 14.9-45.8 months), 21 patients $(10.5 \%)$ demonstrated moderate or greater mitral regurgitation. Freedom from moderate or greater mitral regurgitation at 5 years was $87.0 \% \pm 2.6 \%$. Mean cardiopulmonary bypass and crossclamping times were $182.9 \pm 48.4$ minutes and $110.9 \pm 34.1$ minutes, respectively, demonstrating a significant decrease in both times according to the chronologic date of surgery.
\end{abstract}

Conclusions: Robotic mitral regurgitation repair is technically feasible and efficacious, demonstrating favorable midterm mitral durability and improved procedural times as experience increases. (J Thorac Cardiovasc Surg 2014;148:2773-9)

Robotic mitral valve (MV) repair is a proven and acceptable approach for treating complex MV diseases, especially in centers experienced with minimally invasive cardiac surgery (MICS) techniques and the da Vinci surgical system (Intuitive Surgical, Inc, Sunnyvale, Calif). ${ }^{1,2}$ Studies report excellent early outcomes after robotic MV repair, and the full anatomic correction of the mitral leaflet and annulus using minithoracotomy incision and robotic assistance is a safe and effective approach for all types of degenerative MV pathology. ${ }^{3-6}$

As for the validity of MV repair using MICS, it still needs to be clearly demonstrated that the procedure provides complete surgical correction. To do so, the long-term durability of repaired MV function should be addressed first. However, limited data are available on the long-term

\footnotetext{
From the Departments of Thoracic and Cardiovascular Surgery ${ }^{\mathrm{a}}$ and Cardiology, Asan Medical Center, College of Medicine, University of Ulsan, Seoul, Korea. Disclosures: Authors have nothing to disclose with regard to commercial support. Received for publication May 1, 2014; revisions received June 17, 2014; accepted for publication July 7, 2014; available ahead of print Aug 28, 2014.

Address for reprints: Jae Won Lee, MD, PhD, Department of Cardiovascular Surgery, Asan Medical Center, University of Ulsan, College of Medicine, 88, Olympic-ro 43-gil, Songpa-gu, Seoul 138-736, South Korea (E-mail: jwlee@amc.seoul.kr). $0022-5223 / \$ 36.00$

Copyright (C) 2014 by The American Association for Thoracic Surgery http://dx.doi.org/10.1016/j.jtcvs.2014.07.054
}

efficacy of MV repair using the robotic approach. Although there are several reports on postoperative mortality/ morbidity and long-term freedom from mitral reoperation (ie, repair or replacement), data on the long-term echocardiographic outcomes of MV repair are scarce. Of the published studies on the surgical outcomes of robotic MV repair, only a few include intermediate to long-term echocardiographic follow-up examinations ${ }^{3,4,7,8}$; however, even those studies only report the last echocardiographic results, and only 1 study reported 5-year Kaplan-Meier freedom from reoperation. ${ }^{4}$ In this regard, no study reports the long-term quality of the repaired MVs (eg, regurgitation or stenosis) or freedom from significant mitral regurgitation (MR) recurrence according to results obtained using long-term regular echocardiographic follow-up. Thus, we assessed in the current study our experience of robotic MV repairs, with a specific focus on the midterm echocardiographic outcomes of repaired MVs.

\footnotetext{
METHODS

Patients

Between August 2007 and December 2012, 369 MICS procedures were performed at the Asan Medical Center using the da Vinci surgical system. Of these, 209 patients underwent MV repair. After excluding patients whose MV pathology was diagnosed as mitral stenosis, a total of 200 consecutive patients who had MV repair for MR with or without
} 


\author{
Abbreviations and Acronyms \\ $\mathrm{ACC}=$ aortic crossclamping \\ $\mathrm{AF}=$ atrial fibrillation \\ $\mathrm{CPB}=$ cardiopulmonary bypass \\ $\mathrm{IQR}=$ interquartile range \\ MICS $=$ minimally invasive cardiac surgery \\ MR = mitral regurgitation \\ $\mathrm{MV}=$ mitral valve \\ $\mathrm{TAP}=$ tricuspid annuloplasty \\ TEE $=$ transesophageal echocardiography
}

concomitant tricuspid annuloplasty (TAP) or atrial fibrillation (AF) ablation were identified. The exclusion criteria for robotic MV repair included patients who required an additional cardiac procedure (eg, aortic valve surgery, coronary artery bypass grafting) and patients with risk factors that could affect the MICS approach (eg, peripheral arterial obstructive disease, severely tortuous abdominal aorta, severe cardiomegaly, and difficult chest wall shape for port-access surgery). Robotic MV repairs were performed by a single console surgeon (J.W.L.), along with 5 bedside surgeons. The choice of robot-assisted cardiac surgery primarily depended on the condition of the patient and preferences decided after providing informed consent. We retrospectively reviewed preoperative characteristics, early and late clinical outcomes, and echocardiographic results.

This study was approved by the Asan Medical Center Ethics Committee/Review Board, which waived the requirement for informed patient consent because of the retrospective nature of the analysis.

\section{Operative Technique}

Conventional general anesthesia with dual-lumen endotracheal intubation and single left-lung ventilation was used in all patients. A transesophageal echocardiography (TEE) probe was inserted after intubation, and external defibrillator patches were attached to the back. After percutaneous superior vena caval cannulation through the right internal jugular vein, patients were placed in the supine position with the right chest elevated approximately $30^{\circ}$. Cardiopulmonary bypass (CPB) was established by cannulating the femoral artery and vein. If atherosclerotic burden was identified anywhere in the aortic arch or descending thoracic or abdominal aorta on preoperative computed tomography imaging, an alternative aortic cannulation technique was used (eg, axillary or direct transthoracic ascending aortic cannulation). A 4-cm minithoracotomy horizontal incision was made in the fourth intercostal space in the mid-axillary line, and a dynamic left atrial retractor was placed in the mid-clavicular line. The left arm of the robot was inserted through the third intercostal space in the anterior-axillary line, and the right arm was inserted through the sixth intercostal space in the mid-axillary line. A Chitwood transthoracic aortic clamp (Scanlan International Inc, St Paul, Minn) was placed posterior to the mid-axillary line in the third intercostal space. The chest cavity was flooded with carbon dioxide to mitigate intracavitary air. Femoral cannulation was performed through a $2-\mathrm{cm}$ oblique infrainguinal incision with anterior exposure of the femoral vessels. Vacuum-assisted venous drainage was used during $\mathrm{CPB}$, and myocardial protection was achieved using antegrade cold crystalloid cardioplegic solution (Custodiol HTK; Köhler Chemie GmbH, Bensheim, Germany). After cardioplegic arrest and aortic crossclamping (ACC), the MV was exposed through the interatrial groove. Standard mitral repair techniques were used.

Among patients who required right atriotomy for concomitant TAP or $\mathrm{AF}$ ablation procedures, the superior vena cavae were snared using Bulldog clamps. Concomitant TAPs were conducted in 26 patients $(13.0 \%)$, and concomitant maze procedures were performed in 44 patients $(22.0 \%)$ in whom the modified Cox-maze III procedure with argon-based cryothermy (Cardioblate CryoFlex Surgical Ablation Probe; Medtronic, Inc, Minneapolis, Minn) was performed. Details regarding our modified AF ablation lesion set were previously described.?

\section{Echocardiographic Evaluation}

All patients underwent 2-dimensional echocardiographic analysis and Doppler color-flow imaging using HP Sonos 5500 (Hewlett-Packard, Andover, Mass), Philips iE33 (Philips Medical Systems, Bothell, Wash), and GE vivid 7, E9 (GE Medical System, Horten, Norway) in the 2 months leading up to surgery. Preoperative TEE was also performed to more accurately analyze MV morphology. Immediate postoperative TEE was confirmed by a cardiologist in the operating room after the patient was weaned from $\mathrm{CPB}$, and all patients underwent transthoracic echocardiography before discharge. MR was detected and semiquantitatively graded as mild, moderate, or severe, using color Doppler flow imaging. ${ }^{10}$

\section{Follow-up}

Data were obtained until November 2013, through biannual visits to the outpatient clinic. Early mortality was defined as death within 30 days of surgery. Data on vital status, date of death, and causes of death were obtained from the Korean national registry of vital statistics. Major adverse cardiac and cerebrovascular events were defined as all-cause death or valve-related complications, the latter of which included thromboembolism, reoperation, infective endocarditis, and warfarin-related hemorrhage. Serial echocardiographic follow-up examinations were performed to detect MR recurrence. Recurrent MR was defined as moderate or greater MR (ie, proximal isovelocity surface area radius $>0.4 \mathrm{~cm}$ ).

\section{Statistical Analysis}

Categoric variables are presented as frequencies and percentages. Continuous variables are expressed as the means \pm standard deviations or medians with ranges. The cumulative incidence rates of major event-free survival and freedom from MR were estimated using the Kaplan-Meier method. To assess learning period effects, CPB, ACC, and operative times (skin-to-skin) were reviewed on the basis of the chronologic date of surgery and analyzed using bivariate correlation analysis. All reported $P$ values are 2 -sided. All statistical analyses were performed using SPSS, version 18.0 (IBM, Armonk, NY).

\section{RESULTS}

\section{Baseline Characteristics and Operative Data}

The preoperative patient characteristics are listed in Table 1. Median age was 47 years (interquartile range [IQR], 36-57 years), and $26.5 \%$ of patients were classified with New York Heart Association functional class III/IV. Preoperative MR grade was moderate-to-severe in 17 patients $(8.5 \%)$ and severe in 183 patients $(91.5 \%)$. Two patients underwent prior cardiac surgeries via sternotomy; 1 patient received ventricular septal defect closure, and 1 patient underwent MV repair. In both cases, we used transthoracic clamps with routine antegrade cardioplegic infusion via root cannulation.

Robotic MR repairs were successfully performed in $100 \%$ of patients with no, trivial, or mild residual MR (proximal isovelocity surface area radius $\leq 0.4 \mathrm{~cm}$ ) noted on intraoperative TEE (confirmed by the cardiologist) after weaning off $\mathrm{CPB}$ without intraoperative conversion to 
TABLE 1. Baseline patient profiles $(n=200)$

\begin{tabular}{|c|c|}
\hline Characteristics & n $(\%)$ or mean \pm SD \\
\hline \multicolumn{2}{|l|}{ Demography } \\
\hline Male & $120(60.0)$ \\
\hline Age (y), median (IQR) & $47(36-57)$ \\
\hline Body surface area & $1.7 \pm 0.2$ \\
\hline \multicolumn{2}{|l|}{ Clinical data } \\
\hline NYHA Fc III or IV & $53(26.5)$ \\
\hline $\mathrm{AF}$ & $45(22.5)$ \\
\hline Hypertension & $61(30.5)$ \\
\hline Diabetes mellitus & $12(6.0)$ \\
\hline History of stroke & $8(4.0)$ \\
\hline Chronic obstructive pulmonary disease & $4(2.0)$ \\
\hline Chronic kidney disease & $3(1.5)$ \\
\hline Previous sternotomy & $2(1.0)$ \\
\hline \multicolumn{2}{|l|}{ Echocardiographic data } \\
\hline LV ejection fraction $(\%)$ & $62.66 \pm 6.2$ \\
\hline LV systolic dimension (mm) & $37.7 \pm 5.3$ \\
\hline LV diastolic dimension (mm) & $59.6 \pm 6.4$ \\
\hline LA dimension $(\mathrm{mm})$ & $47.5 \pm 9.0$ \\
\hline Tricuspid regurgitation grade $(>2+)$ & $10(5.0)$ \\
\hline RV-RA $\Delta \mathrm{P}(\mathrm{mm} \mathrm{Hg})$ & $29.6 \pm 11.9$ \\
\hline \multicolumn{2}{|l|}{ MR grade } \\
\hline Severe & $183(91.5)$ \\
\hline Moderate-to-severe & $17(8.5)$ \\
\hline \multicolumn{2}{|l|}{ MV leaflet prolapse subsets } \\
\hline Anterior leaflet & $48(24.0)$ \\
\hline Bileaflet & $47(23.5)$ \\
\hline Posterior leaflet & $105(52.5)$ \\
\hline \multicolumn{2}{|l|}{ Cause of MR } \\
\hline Degenerative & $160(80.0)$ \\
\hline Rheumatic & $18(9.0)$ \\
\hline Infective endocarditis & $18(9.0)$ \\
\hline Congenital & $4(2.0)$ \\
\hline
\end{tabular}

$A F$, Atrial fibrillation; $I Q R$, interquartile range; $L A$, left atrium; $L V$, left ventricle $M R$, mitral regurgitation; $M V$, mitral valve; $N Y H A F c$, New York Heart Association functional class; $R V-R A \Delta P$, right ventricular-right atrial pressure gradient; $S D$, standard deviation.

sternotomy or the diagnosis of mitral stenosis. However, at predischarge, the successful repair rate was $98.0 \%$ because moderate MR was diagnosed in 4 patients (Figure 1). The mean CPB and ACC times were $182.9 \pm 48.4$ minutes and $110.9 \pm 34.1$ minutes, respectively. The mean operative time was $310.9 \pm 73.6$ minutes.

Complex anterior repair techniques were performed on 95 patients $(47.5 \%)$. The variety of repair techniques is shown in Table 2. Annuloplasty rings were used in $99.5 \%$ of patients; the ring was not used in only 1 patient whose annulus size was small $(<26 \mathrm{~mm})$.

\section{Clinical Outcomes}

Postoperative outcomes are reported in Table 3. There was no in-hospital mortality, and the median hospital stay was 6 days. Postoperative complications developed in 17 patients, including reoperation for bleeding in 10 patients $(5.0 \%)$, stroke in 2 patients $(1.0 \%)$, new-onset renal failure

\section{Preoperative Postoperative Last follow-up}

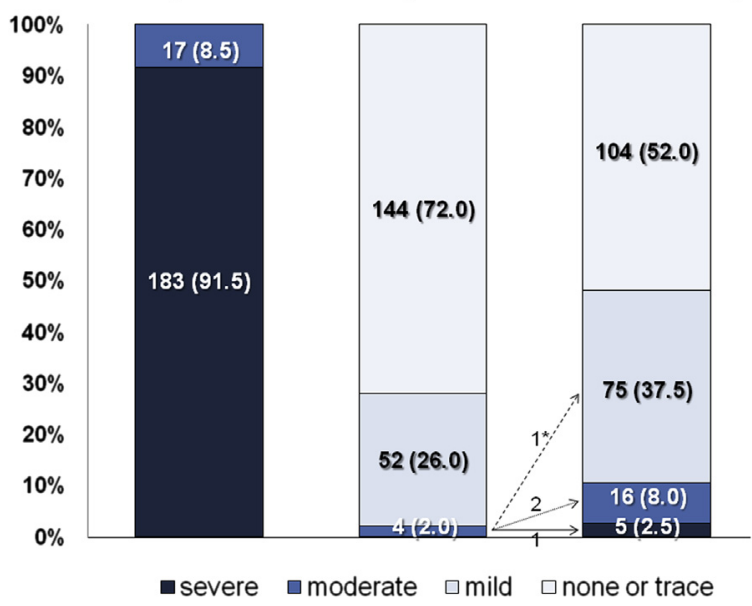

FIGURE 1. Results at the preoperative, immediately postoperative, and last follow-up echocardiographic examinations. *One patient required reoperation for recurring mitral regurgitation.

in 1 patient $(0.5 \%)$, low cardiac output syndrome in 1 patient $(0.5 \%)$, and wound problems in 2 patients $(1.0 \%)$. Reoperation was necessary in 2 patients $(1.0 \%)$ : One reoperation was required because of eccentric MR with hemolysis caused by a loosened artificial chorda on postoperative day 26 , and the other was due to aortic dissection originated from the root cannulation site and required ascending and hemi-arch aortic replacement on postoperative day 3 . Both patients survived to discharge.

TABLE 2. Operative characteristics $(n=200)$

\begin{tabular}{lc}
\hline \multicolumn{1}{c}{ Variable } & n $(\%)$ or mean \pm SD \\
\hline CPB time (min) & $182.9 \pm 48.4$ \\
ACC time (min) & $110.9 \pm 34.1$ \\
Operative time (min) & $310.9 \pm 73.6$ \\
Mitral repair procedure & \\
Ring annuloplasty & $199(99.5)$ \\
Quadrangular/triangular resection & $89(44.5)$ \\
Neochords formation & $91(45.5)$ \\
Commissuroplasty & $70(35.0)$ \\
Sliding annuloplasty & $6(3.0)$ \\
Cleft repair & $5(2.5)$ \\
Chordal transfer & $5(2.5)$ \\
Chordal release & $3(1.5)$ \\
Leaflet augmentation & $2(1.0)$ \\
Papillary muscle repositioning & $1(0.5)$ \\
Concomitant procedures & \\
Maze procedure & $44(22.0)$ \\
TAP & $26(13.0)$ \\
ASD/PFO closure & $25(12.5)$ \\
LA reduction & $19(9.5)$ \\
LA appendage resection & $3(1.5)$ \\
\hline
\end{tabular}

$A C C$, Aortic crossclamping; $A S D$, atrial septal defect; $C P B$, cardiopulmonary bypass $L A$, left atrium; $P F O$, patent foramen ovale; $S D$, standard deviation; $T A P$, tricuspid annuloplasty. 
TABLE 3. Postoperative outcomes and complications $(n=200)$

\begin{tabular}{|c|c|}
\hline Variable & n $(\%)$ or mean \pm SD \\
\hline Early death $(<30 \mathrm{~d})$ & $0(0)$ \\
\hline Hospital stay, d (IQR) & $6(5-8)$ \\
\hline ICU stay, h (IQR) & $23(20-40)$ \\
\hline Mechanical ventilation (>24 h) & $10(5.0)$ \\
\hline \multicolumn{2}{|l|}{ Complications } \\
\hline Reoperation for bleeding & $10(5.0)$ \\
\hline $\mathrm{ARF}$ requiring dialysis & $1(0.5)$ \\
\hline Low cardiac output & $1(0.5)$ \\
\hline Stroke & $2(1.0)$ \\
\hline Thromboembolic event & $1(0.5)$ \\
\hline Thoracotomy wound & $1(0.5)$ \\
\hline Groin wound & $1(0.5)$ \\
\hline Permanent pacemaker insertion & $0(0)$ \\
\hline Pneumonia & $0(0)$ \\
\hline Reoperation & $2(1.0)$ \\
\hline For $\mathrm{MR}^{*}$ & $1(0.5)$ \\
\hline Other (eg, aortic dissection) $\dagger$ & $1(0.5)$ \\
\hline Late mortality & $4(2.0)$ \\
\hline \multicolumn{2}{|c|}{ Last echocardiographic data $(>6 \mathrm{mo})(\mathrm{n}=187)$} \\
\hline LV ejection fraction $(\%)$ & $59.7 \pm 5.6$ \\
\hline LV systolic dimension (mm) & $32.1 \pm 5.1$ \\
\hline LV diastolic dimension (mm) & $49.1 \pm 5.2$ \\
\hline LA dimension $(\mathrm{mm})$ & $39.6 \pm 6.9$ \\
\hline RV-RA $\Delta \mathrm{P}(\mathrm{mm} \mathrm{Hg})$ & $21.7 \pm 6.5$ \\
\hline
\end{tabular}

$A R F$, Acute renal failure; $I Q R$, interquartile range; $I C U$, intensive care unit; $L A$, left atrial; $L V$, left ventricular; $M R$, mitral regurgitation; $R V$ - $R A \Delta P$, right ventricular-right atrial pressure gradient; $S D$, standard deviation. *One patient underwent reoperation for MR due to a loosened artificial chorda. $\dagger$ Ascending aorta and hemi-arch replacement was performed for aortic dissection that was detected on postoperative day 3 .

Clinical follow-up ( $>6$ months) was completed in 193 patients $(96.5 \%)$. Late death occurred in 4 patients. At a median of 31.4 months (IQR, 12.4-42.3 months), freedom from major adverse cardiac and cerebrovascular events at 5 years was $87.7 \% \pm 5.1 \%$ (Figure 2).

\section{Echocardiographic Outcomes}

Serial echocardiographic data extending 6 months or more from the time of surgery were available for 187 patients $(93.5 \%)$. Among 4 patients with moderate MR at predischarge, 1 underwent reoperation, 1 spontaneously developed mild MR, 1 developed severe MR, and 1 maintained moderate MR (Figure 1). Over a median follow-up period of 29.6 months (IQR, 14.9-45.8 months), 21 patients $(10.5 \%)$ developed moderate or greater MR (Figure 1). Freedom from moderate or greater MR at 5 years was $87.0 \% \pm 2.6 \%$ (Figure 3 ).

\section{Change in Procedural Time by the Number of Cases}

Both CPB and ACC times decreased as experience increased, demonstrating statistical significance according to the chronologic date of the procedure $(r=-0.225$, $P=.001$ and $r=-0.378, P<.001$, respectively) (Figure 4, $A$ and $B$ ). Main procedural time also improved.

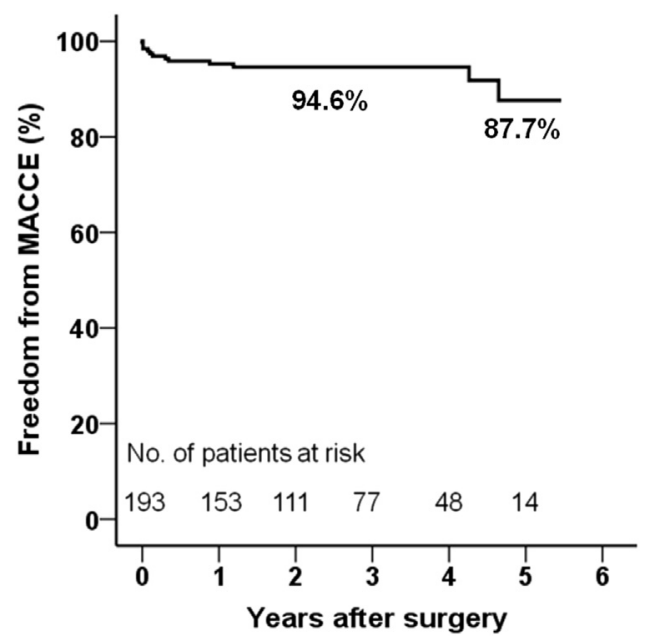

FIGURE 2. Kaplan-Meier curve for freedom from major adverse cardiac and cerebrovascular events. MACCE, Major adverse cardiac and cerebrovascular events.

However, total operative time (skin-to-skin), which includes preparation time required for robot docking and bleeding control, did not improve $(r=0.121, P=.089)$ (Figure 4, C).

\section{DISCUSSION}

The advantages of MICS, such as decreased postoperative pain and length of hospital stay, and improved cosmesis, patient satisfaction, and postoperative recovery, are well known. ${ }^{11,12}$ The da Vinci surgical system facilitates MICS by using 3-dimensional high-definition imaging, sophisticated micro-instrumentation with wristlike articulation, and tremor filtration, thereby allowing MV repair with the least degree of surgical trauma. $4,5,7,13$ Despite these obvious benefits and favorable results, its

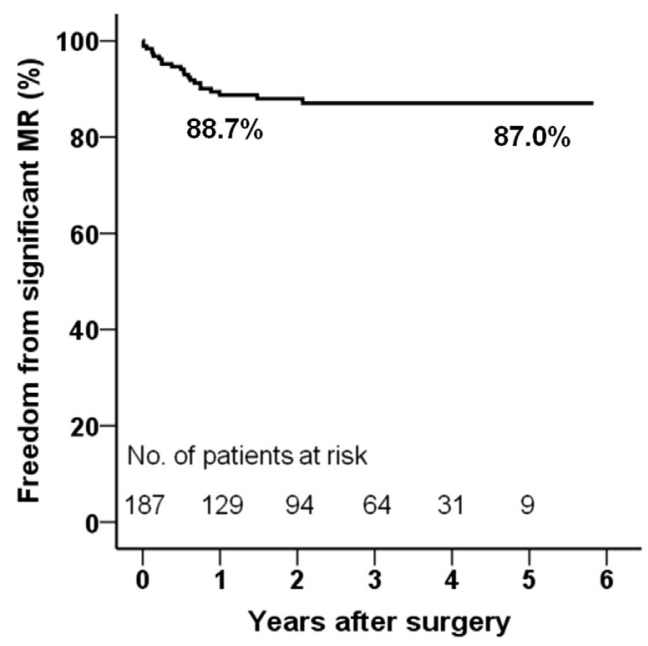

FIGURE 3. Kaplan-Meier curve for freedom from moderate or greater MR. $M R$, Mitral regurgitation. 

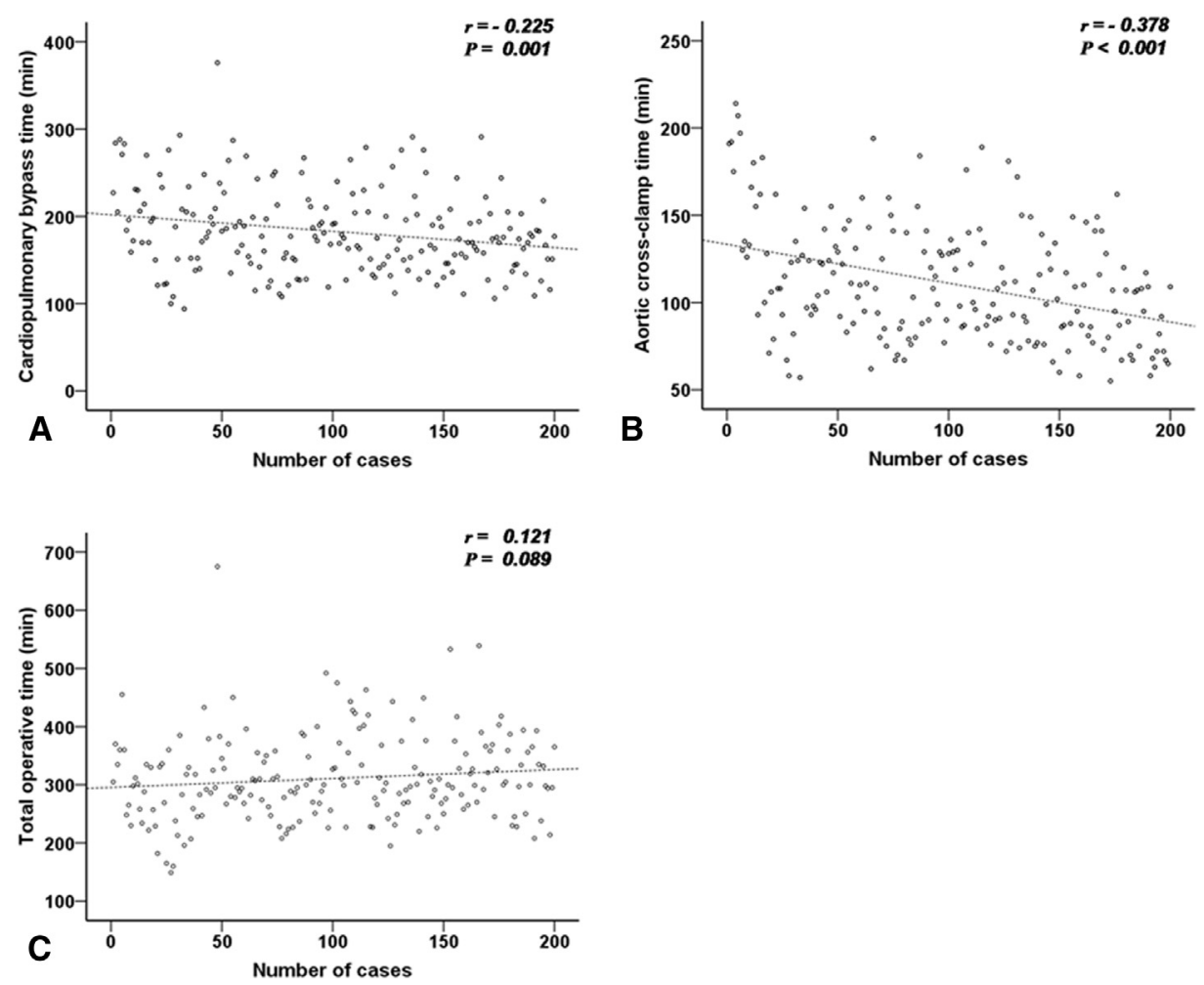

FIGURE 4. Pearson's correlation curves for changes in (A) cardiopulmonary bypass time (CPB), (B) aortic cross-clamp time (ACC), and (C) total operative times based on the chronologic date of mitral repairs.

active use is limited to only a few centers in Asia primarily because of concerns about safety, complexity, prolonged surgical time, and the high cost of the procedure..$^{14,15}$ However, these concerns are primarily related to the uncertainty of performing various repair techniques using a telemanipulative device that lacks tactile feedback and whether MV repair can be successfully and completely performed.

\section{Safety and Efficacy of Mitral Valve Repair}

Safety issues regarding robotic MICS were frequently raised by critics during the early days of development. The general concerns were that a reduced surgical field and using instrumentation without tactile feedback would increase the complexity of the procedure and surgical risks. The increased incidence of stroke was particularly important and related to the use of retrograde perfusion via femoral arterial cannulation during MICS. ${ }^{16,17}$ Nonetheless, the rapid development and refinement of techniques enabled complex MICS valve surgery to be performed with results equivalent to those of conventional valve surgery at experienced centers. ${ }^{2}$ According to a recent systematic review of studies on robotic MV surgery, ${ }^{6}$ the majority of studies report early mortality rates less than $1.0 \%$. In agreement with these reports, this study reports no in-hospital mortality and low rates of major complications, including a stroke incidence of $1.0 \%$ (Table 3 ).
As claimed by Suri and colleagues, ${ }^{18}$ preoperative computed tomography screening and avoidance of femoral arterial cannulation in the presence of atherosclerotic burden are solutions to the stroke problem.

To validate robotic MV repair, both safety issues and surgical completeness need to be addressed. According to a recent review, ${ }^{6}$ the rate of early postoperative failure that required reoperation ranges from $1.5 \%$ to $5.4 \%$, and immediate postoperative echocardiography demonstrates that $81.7 \%$ to $97.6 \%$ of patients have no or only trace MR. We report a successful MV repair rate of $98.0 \%$ during the immediate postoperative period without intraoperative conversion to sternotomy. Mitral reoperation was required in only 1 patient (Table 3 ).

In regard to the durability of the repaired MV using the MICS approach, most previous studies focused only on survival and mitral reoperation rates. ${ }^{19}$ To the best of our knowledge, the present study is the first to assess the midterm echocardiographic durability of MV on the basis of the results of regular follow-up examinations. Freedom from significant MR at 5 years was $87.0 \% \pm 2.6 \%$ (Figure 3). This seems to be good in comparison with recent data published by our institution, ${ }^{20}$ where serial echocardiographic follow-up was completed in more than $90 \%$ of patients who underwent MV through minithoracotomy or sternotomy and 5-year freedom from MR recurrence rates were $86.1 \%$ and $85.3 \%$, respectively. 


\section{Various Repair Techniques and Other Cardiac Procedures}

In MV repair, anterior or bileaflet prolapse is considered more difficult to repair than posterior leaflet prolapse, requiring more advanced techniques and greater expertise, and is associated with an increased risk of mitral reoperation. ${ }^{21-23}$ The repair of anterior prolapse using robotic MV repair is also controversial. The general opinion is that complex repair techniques, such as neochords formation, are difficult to perform using robotic instruments because of the lack of tactile feedback. ${ }^{3}$ Although the proportion of anterior leaflet involvement was relatively high $(47.5 \%)$ (Table 1), various repair techniques could be used. Furthermore, anterior leaflet involvement did not increase the risk of MR recurrence according to the univariate Cox regression analysis (relative risk, 1.07; 95\% confidence interval, 0.47-2.48; $P=.87$ ).

In support of our results, the largest study on robotic MV repair for anterior or bileaflet prolapse by Rodriguez and colleagues $^{3}$ reported that these procedures can be safely performed without device-related complications. Suri and colleagues ${ }^{18}$ also concluded that robotic MV repair allows the complete anatomic correction of all types of leaflet prolapse using repair techniques that are identical to those used in open approaches.

Another important finding of the present study is that the rates of other concomitant cardiac procedures were high (Table 2). Concomitant AF ablation was performed on 44 patients $(22.0 \%)$, which is higher than in the study by Nifong and colleagues, ${ }^{24}$ in which the concomitant CryoMaze procedure was performed on $15.9 \%$ of patients. Among 45 patients with preoperative AF, ablation procedures were performed in $44(97.8 \%)$. These results illustrate that various repair techniques and concomitant procedures can be performed using the da Vinci system.

\section{Learning Period Effect}

There was a definite improvement in the main procedural time as experience increased (Figure 4). However, total operative time (skin-to-skin), which included time for preparation and bleeding control, demonstrated no significant improvement. In 2002, we started using the AESOP 3000 system (Computer Motion, Santa Barbara, Calif) and reported favorable results. ${ }^{20}$ Because the same repair techniques were performed using the da Vinci approach, the learning curve for the console surgeon was virtually nonexistent. However, 5 separate bedside surgeons were involved in the early period of our robotic MICS program, rather than only a dedicated bedside surgeon. It is well known that the participation of a skilled bedside surgeon is useful and critical to robotic operations, ${ }^{18}$ and a study reported that the presence of a dedicated bedside surgeon improves operative times during robotic MV surgery. ${ }^{25}$
The high rate of reoperation for bleeding complications $(5.0 \%)$ (Table 3), which is the most critical weakness of our data, could be due to the absence of a dedicated bedside surgeon. All reoperations for bleeding were performed through the previous working incision without thoracotomy extension, and the bleeding foci mainly included the port sites and intercostal muscles.

Surgical volume and learning curve effects are important for maintaining surgical quality. In this regard, our robotic MICS program demonstrates a significant weakness because of the 5 different bedside surgeons and different team members (ie, anesthesiologists and scrub nurses). In an effort to improve the quality of our robotic MICS program, we adopted several new institutional strategies in 2012. Robotic MICS is now performed by 1 dedicated bedside surgeon, and we now use the Glauber clamp (Sorin Group, Saluggia, Italy) ${ }^{26}$ to reduce bleeding control time and the risk of port-site bleeding, because this clamp obviates the need for an extra port incision and facilitates easier bleeding control. After these changes, 50 consecutive robotic MV repairs were performed, and there were no instances of bleeding complications.

The learning curves for cardiac surgery tend to develop when new assistive technologies are introduced. The learning curve is especially steep for robotic MV repairs: thus, using a team of highly experienced members with a strong history of good outcomes after MV repair via sternotomy or minithoracotomy is of the utmost importance before initiating a robotic repair program. ${ }^{18}$

\section{Study Limitations}

This study is subject to the inherent limitations of retrospective observational studies, and the study population was relatively small. As previously mentioned, the number of patients is small mainly because robotic MV repair is still limited to only a few centers in Korea.

\section{CONCLUSIONS}

Robotic MV repair is technically feasible and efficacious, and the repaired MV demonstrates favorable midterm echocardiographic durability. Moreover, procedural times improve as the experience of the clinicians increases. In addition, it is possible to perform various repair techniques and concomitant cardiac procedures that are identical to those used in open approaches. Long-term follow-up studies are needed to confirm these observations.

\section{References}

1. Mohr FW, Onnasch JF, Falk V, Walther T, Diegeler A, Krakor R, et al The evolution of minimally invasive valve surgery-2 year experience. Eur J Cardiothorac Surg. 1999; 15:233-8.

2. Falk V, Cheng DC, Martin J, Diegeler A, Folliguet TA, Nifong LW, et al. Minimally invasive versus open mitral valve surgery: a consensus statement of the international society of minimally invasive coronary surgery (ISMICS) 2010. Innovations (Phila). 2011;6:66-76. 
3. Rodriguez E, Nifong LW, Chu MW, Wood W, Vos PW, Chitwood WR. Robotic mitral valve repair for anterior leaflet and bileaflet prolapse. Ann Thorac Surg. 2008;85:438-44.

4. Chitwood WR Jr, Rodriguez E, Chu MW, Hassan A, Ferguson TB, Vos PW, et al. Robotic mitral valve repairs in 300 patients: a single-center experience. J Thorac Cardiovasc Surg. 2008;136:436-41.

5. Murphy DA, Miller JS, Langford DA, Snyder AB. Endoscopic robotic mitral valve surgery. J Thorac Cardiovasc Surg. 2006;132:776-81.

6. Seco M, Cao C, Modi P, Bannon PG, Wilson MK, Vallely MP, et al. Systematic review of robotic minimally invasive mitral valve surgery. Ann Cardiothorac Surg. 2013;2:704-16.

7. Nifong LW, Chu VF, Bailey BM, Maziarz DM, Sorrell VL, Holbert D, et al. Robotic mitral valve repair: experience with the da Vinci system. Ann Thorac Surg. 2003;75:438-43

8. Cheng W, Fontana GP, De Robertis MA, Mirocha J, Czer LS, Kass RM, et al. Is robotic mitral valve repair a reproducible approach? J Thorac Cardiovasc Surg. 2010;139:628-33.

9. Lee JW, Choo SJ, Kim KI, Song JK, Kang DH, Song JM, et al. Atrial fibrillation surgery simplified with cryoablation to improve left atrial function. Ann Thorac Surg. 2001;72:1479-83.

10. Lancellotti P, Moura L, Pierard LA, Agricola E, Popescu BA, Tribouilloy C, et al. European association of echocardiography recommendations for the assessment of valvular regurgitation. Part 2: Mitral and tricuspid regurgitation (native valve disease). Eur J Echocardiogr. 2010;11:307-32.

11. Iribarne A, Russo MJ, Easterwood R, Hong KN, Yang J, Cheema FH, et al. Minimally invasive versus sternotomy approach for mitral valve surgery: a propensity analysis. Ann Thorac Surg. 2010;90:1471-7.

12. Holzhey DM, Shi W, Borger MA, Seeburger J, Garbade J, Pfannmuller B, et al. Minimally invasive versus sternotomy approach for mitral valve surgery in patients greater than 70 years old: a propensity-matched comparison. Ann Thorac Surg. 2011;91:401-5.

13. Mihaljevic T, Jarrett CM, Gillinov AM, Williams SJ, DeVilliers PA, Stewart WJ, et al. Robotic repair of posterior mitral valve prolapse versus conventional approaches: potential realized. J Thorac Cardiovasc Surg. 2011;141:72-80, e1-4.

14. Robicsek F. Robotic cardiac surgery: quo vadis? J Thorac Cardiovasc Surg. 2003; 126:623-4
15. Diodato MD Jr, Damiano RJ Jr. Robotic cardiac surgery: overview. Surg Clin North Am. 2003;83:1351-67, ix.

16. Gammie JS, Zhao Y, Peterson ED, O'Brien SM, Rankin JS, Griffith BP Less-invasive mitral valve operations: trends and outcomes from The Society of Thoracic Surgeons Adult Cardiac Surgery Database. Ann Thorac Surg. 2010;90:1401-8.

17. Mariscalco G, Musumeci F. The minithoracotomy approach: a safe and effective alternative for heart valve surgery. Ann Thorac Surg. 2014;97:356-64.

18. Suri RM, Burkhart HM, Daly RC, Dearani JA, Park SJ, Sundt TM, et al Robotic mitral valve repair for all prolapse subsets using techniques identical to open valvuloplasty: Establishing the benchmark against which percutaneous interventions should be judged. J Thorac Cardiovasc Surg. 2011;142:970-9.

19. Modi P, Hassan A, Chitwood WR Jr. Minimally invasive mitral valve surgery: a systematic review and meta-analysis. Eur J Cardiothorac Surg. 2008;34:943-52.

20. Yoo JS, Kim JB, Jung SH, Choo SJ, Chung CH, Lee JW. Echocardiographic assessment of mitral durability in the late period following mitral valve repair: minithoracotomy versus conventional sternotomy. J Thorac Cardiovasc Surg. 2014; $147: 1547-52$

21. David TE, Ivanov J, Armstrong S, Christie D, Rakowski H. A comparison of outcomes of mitral valve repair for degenerative disease with posterior, anterior, and bileaflet prolapse. J Thorac Cardiovasc Surg. 2005;130:1242-9.

22. Braunberger E, Deloche A, Berrebi A, Abdallah F, Celestin JA, Meimoun P, et al. Very long-term results (more than 20 years) of valve repair with Carpentier's techniques in nonrheumatic mitral valve insufficiency. Circulation. 2001;104 I8-11.

23. Mohty D, Orszulak TA, Schaff HV, Avierinos JF, Tajik JA, Enriquez-Sarano M Very long-term survival and durability of mitral valve repair for mitral valve prolapse. Circulation. 2001;104:I1-7.

24. Nifong LW, Rodriguez E, Chitwood WR Jr. 540 consecutive robotic mitral valve repairs including concomitant atrial fibrillation cryoablation. Ann Thorac Surg. 2012;94:38-43.

25. Charland PJ, Robbins T, Rodriguez E, Nifong WL, Chitwood RW. Learning curve analysis of mitral valve repair using telemanipulative technology. J Thorac Cardiovasc Surg. 2011;142:404-10.

26. Glauber M, Karimov JH. A completely detachable aortic clamping instrument for minimally invasive cardiac surgery. Innovations (Phila). 2010;5:309-10. 